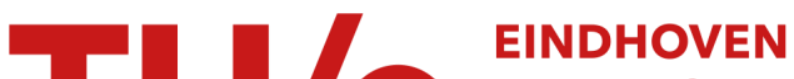 UNIVERSITY OF TECHNOLOGY
}

\section{Helical axes of passive knee joint motions}

Citation for published version (APA):

Blankevoort, L., Huiskes, H. W. J., \& Lange, de, A. (1990). Helical axes of passive knee joint motions. Journal of Biomechanics, 23(12), 1219-1229. https://doi.org/10.1016/0021-9290(90)90379-H

DOI:

10.1016/0021-9290(90)90379-H

Document status and date:

Published: 01/01/1990

\section{Document Version:}

Publisher's PDF, also known as Version of Record (includes final page, issue and volume numbers)

\section{Please check the document version of this publication:}

- A submitted manuscript is the version of the article upon submission and before peer-review. There can be important differences between the submitted version and the official published version of record. People interested in the research are advised to contact the author for the final version of the publication, or visit the $\mathrm{DOI}$ to the publisher's website.

- The final author version and the galley proof are versions of the publication after peer review.

- The final published version features the final layout of the paper including the volume, issue and page numbers.

Link to publication

\section{General rights}

Copyright and moral rights for the publications made accessible in the public portal are retained by the authors and/or other copyright owners and it is a condition of accessing publications that users recognise and abide by the legal requirements associated with these rights.

- Users may download and print one copy of any publication from the public portal for the purpose of private study or research.

- You may not further distribute the material or use it for any profit-making activity or commercial gain

- You may freely distribute the URL identifying the publication in the public portal.

If the publication is distributed under the terms of Article $25 \mathrm{fa}$ of the Dutch Copyright Act, indicated by the "Taverne" license above, please follow below link for the End User Agreement:

www.tue.nl/taverne

Take down policy

If you believe that this document breaches copyright please contact us at:

openaccess@tue.nl

providing details and we will investigate your claim. 


\title{
HELICAL AXES OF PASSIVE KNEE JOINT MOTIONS
}

\author{
L. Blankevoort; R. Huiskes and A. De Lange† \\ Biomechanics Section. Institute of Orthopaedics, University of Nijmegen. P.O. Box 9101, 6500 HB \\ Nijmegen, The Netherlands
}

\begin{abstract}
The purpose of this study was to determine finite helical axes for passive knee joint motions in vitro and to evaluate the descriptive value of the finite helical axes for step-by-step flexion motions, with respect to consistency and reproducibility. An accurate Roentgenstereophotogrammetric system was used for motion measurements. Four knees were tested in a motion and loading rig with one and the same experimental protocol. A fifth specimen was used to study the effects of some of the experimental conditions on the axis parameters. On the basis of earlier reported motion characteristics in terms of Euler rotations and translations, two motion pathways were chosen to be reported here: a flexion motion with an internal torque of $3 \mathrm{Nm}$ and one with an external torque of $3 \mathrm{Nm}$ on the tibia. The positions and orientations of the axes were described relative to the insertions of the four major ligaments and the geometry of the articular surfaces of the femur, and also as intersections with a medial and a lateral sagittal plane. The threedimensional patterns of the helical axes of the four knee specimens were found to be highly reproducible and consistent for each of the two motion pathways. The axis patterns were not unique, but reflected the particular combination of flexion and axial rotation for each particular motion pathway. Although small. the helical translations indicated medial motions of the tibia relative to the femur. This medial helical translation was more pronounced for the internal pathway compared with the external pathway. Above $70^{\circ}$ flexion, the axes move posteriorly relative to the femur.
\end{abstract}

\section{INTRODUCTION}

The rotation axis or, more precisely, the helical axis, is a useful tool for describing knee joint motions, al. though its popularity in the contemporary biomechanics literature is affected by the poor consistency and reproducibility of the early results (e.g. Blacharski et al., 1975). 'ihe purpose of this paper is to describe finite helical axes for passive step-by-step flexion motions, on the basis of earlier reported passive in vitro motion characteristics of human knees (Blankevoort et ul., 1988), and to evaluate the descriptive value of the finite helical axis with respect to its consistency and reproducibility.

In most kinematic analyses of human joints, a continuous motion is simulated by a sequence of finite motion steps of one bone of the joint relative to the other. Each joint position can be described by three translational components and three Euler (or Cardan) rotations, relative to the coordinate systems applied to the two bones comprising the joint. Another descriptive method is the finite helical axis, which describes a motion step as a rotation about and a translation along an axis. In the Euler description method, the values of the translations depend on the particular choice of the locations of the origins of the coordinate systems (Blankevoort et al., 1988). The values of the Euler rotations about the axes of the coordinate system depend on the specified rotation sequence and the precise identification of the directions of the

Received in final form 31 May 1990.

- Author to whom correspondence should be addressed.

† Presently at the TNO Leather and Shoe Research Institute. Waalwijk. The Netherlands. coordinate axes relative to the joint anatomy (Blankevoort et al., 1988). Nevertheless, with a generally accepted agreement on the definition of the coordinate system, the rotation parameters are useful for charactcrizing knec joint motion in relation to anatomical descriptions (Grood and Suntay, 1983). Motion descriptions by using (finite) centers of rotations for planar motions or by (finite) helical axes for spatial motions, are in fact independent of the chosen coordinate systems, since the value of the rotation about the rotation center or the helical axis and the value of the translation along the axis are invariant to coordinate transformations. Although the position of a rotation center, or the position and the direction of a helical axis, are represented relative to a coordinate system, both can be described relative to the anatomical landmarks of a joint, in which case the precise identification of the coordinate axes is of less importance. The translations along the helical axis represent a real (invariant) translation in three-dimensional space, as opposed to the translations of the origins of the coordinate systems. However, the helical axis description method also has disadvantages. The axis is not defined for pure translations and the position and direction parameters of the helical axis are highly susceptible to measurement errors if the rotations are small (Woltring et al., 1985; de Lange et al., 1990a).

The helical axes as obtained with three-dimensional techniques such as measurements with six degrees of freedom spatial linkages (e.g. Shiavi et al., 1987a, b), Roentgenstereophotogrammetry (van Dijk et al., 1979; van Dijk, 1983), or optoelectronic techniques in combination with data smoothing (e.g. Ramakrishnan et al., 1987), were not always consistent, despite sufficient accuracy or noise reduction. The poor reproducibility of the helical axes is probably caused by the 
variations of the spatial motions between the individual specimens within a study. On the other hand however, if the motion patterns are similar between individual specimens, then the helical axes should also be similar. This study was therefore focused on helical axes of passive knee joint motions, which were found to be reproducible between individual joint specimens.

\section{METHODS}

\section{Experimental procedure}

The finite helical axes were determined from position data of bone markers of in titro experiments on four human knees, numbered 1-4, of which two were bilateral (specimens 3 and 4). The experiments and the resulting kimematic characteristics in terms of Euler rotations and translations were described extensively in a previous paper (Blankevoort et al., 1988). The experimental procedures are summarized in this section.

The freshly frozen and pre-experimentally thawed knee specimen was cut $15 \mathrm{~cm}$ above and below the joint line and fixed into a motion and loading apparatus, allowing the tibia six degrees of freedom of motion relative to the femur. The flexion angle was prescribed. The joint was moved through flexion in subsequent flexion steps while external loads were applied. At each flexion angle the relative positions of the bones were measured by using Roentgenstereophotogrammetry (RSA; Selvik, 1974). For this purpose six tuntalum pellets were inserted into the cortex of each bone prior to the experiments. The two-dimensional positions of the projections of these markers on the Roentgen films, as exposed by two separate Roentgen tubes, were measured by a two-dimensional digitizer and used to calculate the spatial coordinates of the markers. The three-dimensional marker coordinates were used to calculate the kinematic parameters which described the motion from one position of the joint to another. The accuracy of the spatial positions of the markers is reported to be better than $0.05 \mathrm{~mm}$ (standard deviation) (Blankevoort et al., 1988). The coordinate system was defined by a calibration procedure for the unloaded joint in extension (Blankevoort et al., 1988). The origins of both the tibial and femoral coordinate systems coincided for the joint in extension and were located at the tibial insertion of the most posterior bundle of the anterior cruciate ligament. The positive $x$-axis pointed medially, the positive $y$-axis proximally and the positive $z$-axis anteriorly.

Each knee was tested in a number of flexion series with a specific loading configuration. A flexion series consisted of a number of subsequent flexion positions from extension to approximately $95^{\circ}$ of flexion. The two motion pathways reported here were an external and an internal motion pathway, which were obtained by loading the joint with an external torque or an internal torque of $3 \mathrm{Nm}$ about the long axis of the tibia during the flexion motion. These two flexion motions along the limits of internal and external rotation were found to be reproducible between individual joint specimens and were not susceptible to additional external loads (Blankevoort et al., 1988).

After the experiments, the joint was dissected and the ligaments were exposed. The peripheral fiber bundles of the four major ligaments were macroscopically identified and their insertions were marked by placing additional tantalum pellets at the corresponding extremes of the insertion area. An additional Roentgen double exposure was evaluated to determine the coordinates of these ligament markers relative to the femoral and tibial coordinate system, respectively (van Dijk et al., 1979).

Finite helical motion is described by the rotation $\theta$ about and the transiation $t$ along the helical axis, its (unit) direction vector $\mathbf{n}$ and the position vector $\mathbf{s}$ (Fig. 1). The ratio $t / \theta$ is called the pitch of the helical axis and is used to normalize the helical translation relative to the helical rotation. The pitch is positive if the translation $t$ is performed in the direction of the (unit) direction vector $\mathbf{n}$. The helical axis parameters were calculated from the coordinates of the markers at the two subsequent joint positions for each finite motion step (Selvik, 1974). The marker position data were the same as in the previous study, where the Euler rotations and the translations were reported (Blankevoort et al., 1988). The position and direction vectors of the helical axis could be represented relative to the tibial coordinate system, as if the femur were moving relative to a fixed tibia, or relative to the femoral coordinate system, as if the tibia were moving relative to a fixed femur. The positions and directions were also represented relative to the ligament insertions, which were measured with the RSA system and

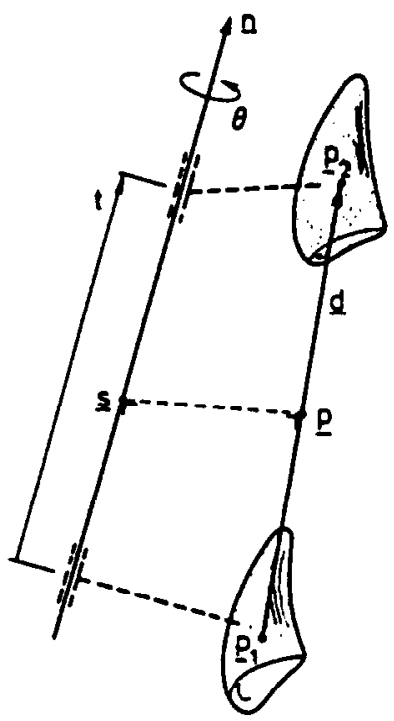

Fig. I. Finite helical axis. The axis parameters are: $n$-the unit direction vector; 5 -the position of the axis; 0 -the rotation about the axis; $t$-the translation along the axis (reproduced with permission from Woltring et al., 1985). Note: vectors are underlined in the figure. 
the geometry of the articular surfaces, which were measured with stereophotogrammetric techniques (Huiskes et al., 1985; Meijer et al., 1989). The third representation, which was also used in this study, gave the intersections of the axes with two sagittal planes, which were located $50 \mathrm{~mm}$ lateral and $50 \mathrm{~mm}$ medial off the center of the joint. Each axis was associated with particular rotation and translation magnitudes.

Specimens 1 and 2 were tested with seven variable flexion steps ranging from 5 to $30^{\circ}$, whereas specimens 3 and 4 were tested with six, more-or-less constant, flexion steps between 15 and $20^{\circ}$. This might have given rise to flexion-step related differences in the comparison between the individual specimens. Therefore, an additional experiment was performed on a fifth knee specimen. The same experimental protocol was used, but in this case only an internal motion pathway was measured with small flexion steps. Instead of 6 or 7 flexion steps, the joint was moved through flexion in 25 steps. According to Woltring et al. (1985), the effect of the measurement errors on the direction and position parameters of the helical axis is inversely proportional to the magnitude of the motion step. In order to exclude this effect in the present comparison of the variable motion steps, a noise reduction of the position data of the femoral markers relative to the tibial coordinate system was applied by using GCVSPL (generalized cross-validatory spline smoothing: Woltring. 1986). This technique uses a quintic spline whereby the amount of smoothing is determined by means of generalized cross-validation. This procedure has been applicd successfully by de Lange et al. (1990b) for the analysis of carpal bone motions, using RSA. From the smoothed data set with small motion steps, two data sets of joint positions were selected, which were similar to the sets of joint positions with large motion steps of the first four joints. The helical axes of the three data sets of the same motion, with small and large motions steps, are compared.

\section{ACCURACY}

The accuracy of the helical axis parameters depends on the accuracy of the spatial reconstruction of the markers, the number of markers, the relative positions of the markers in the bone, the rotation about and the translation along the axis (Woltring et al., 1985). The precision of the helical axis parameters and the derived parameters were estimated by remeasuring the Roentgenograms of particular flexion series and by actually repeating particular flexion series.

The Roentgenograms of two flexion series of specimen 4 were digitized for the second time and the process of the reconstruction of the marker positions and the calculation of the helical axis parameters was repeated. Consequently, two sets of parameters were obtained, the original and the remeasured set. These two sets of duplicate values were then used to calcu- late, for each parameter, the standard deviation according to (Mikhail, 1976):

$$
\text { S.D. }=\left[\frac{\sum_{i=1}^{n}\left(P_{i 1}-P_{i 2}\right)^{2}}{2 n}\right]^{1 / 2}
$$

in which

$$
\begin{aligned}
\text { S.D. } & =\text { standard deviation } \\
P_{i 1} & =\text { result of first measurement } \\
P_{12} & =\text { result of second measurement } \\
n & =\text { number of duplicate values. }
\end{aligned}
$$

Secondly, two fexion series of specimen 4 were repeated as a whole, thus in fact repeating a part of the experiment. The two sets of helical axis parameters, from the original and repeated experiments, were again used to calculate the standard deviations. The joint specimen remained fixed in the motion rig between the two measurements.

The standard deviations of the helical axis parameters, i.e. rotation, translation, direction and position, are listed in Table 1 , together with the standard deviations of the pitch and the intersections with the sagittal planes. The values for the repeated reconstruction are estimates of the precision of the RSA system and those of the repeated experiment estimates for the reproducibility of the experiment as a whole. The rotation step for both accuracy tests varied between 15 and $20^{\circ}$. The direction and position errors are inversely proportional to the amount of helical rotation (Woltring et al., 1985). For the smallest rotation steps in the present study, namely $4^{\circ}$, the direction and position errors can be approximately four to five times higher than listed in Table 1 . Because the intersections of the axis with the sagittal planes depend on both the direction and the position of the axis, the intersection errors will also be inversely proportional to the amount of helical rotation, if the axis intersects perpendicularly with the sagittal plane. Higher intersection errors may occur with oblique intersections, depending on the angle of intersection. Since the relative error of the helical rotation is much smaller than the relative pitch error, the absolute pitch error is approximately equal to the translation error divided by the amount of helical rotation, which means that the pitch error will vary between 0.03 and $0.007 \mathrm{~mm}$ per degree for rotation angles between 5 and $30^{\circ}$ respectively.

\section{RESUL.TS}

The finite helical axes for an internal motion pathway with small motion steps (specimen 5) are shown relative to the tibial anatomy in Fig. 2 (a) and relative to the femoral anatomy in Fig. 2(b). In Figs 2(a) and (b) the location of the coordinate axes and the two sagittal planes are indicated. In the subsequent representation of the results, the helical axes are represented relative to the femur. Figure 3 shows the internal rotation as 
Table 1. Standard deviations of the finite helical axis parameters for the repeated reconstruction of the Roentgenstereophotogrammetric measurements and the repeated experiment (specimen 4)

\begin{tabular}{lllc}
\hline & & \multicolumn{2}{c}{ Standard deviations } \\
\cline { 3 - 4 } & & $\begin{array}{c}\text { Repeated } \\
\text { reconstruction } \\
n=11\end{array}$ & $\begin{array}{c}\text { Repeated } \\
\text { experiment } \\
n=12\end{array}$ \\
\hline Rotation & (degree) & 0.11 & 0.10 \\
Translation & (mm) & 0.14 & 0.20 \\
Direction & (degree) & 0.39 & 0.97 \\
Position & & & \\
& $x(\mathrm{~mm})$ & 0.10 & 0.18 \\
Pitch & $y(\mathrm{~mm})$ & 0.26 & 0.23 \\
Intersections & $z(\mathrm{~mm})$ & 0.22 & 0.32 \\
Lateral & & 0.008 & 0.012 \\
$x=-50 \mathrm{~mm}$ & & & \\
& $y(\mathrm{~mm})$ & & 0.99 \\
Medial & $=(\mathrm{mm})$ & 0.33 & 0.45 \\
$x=50 \mathrm{~mm}$ & & 0.24 & \\
& $y(\mathrm{~mm})$ & & 0.68 \\
& $z(\mathrm{~mm})$ & 0.44 & \\
\hline
\end{tabular}

(a)

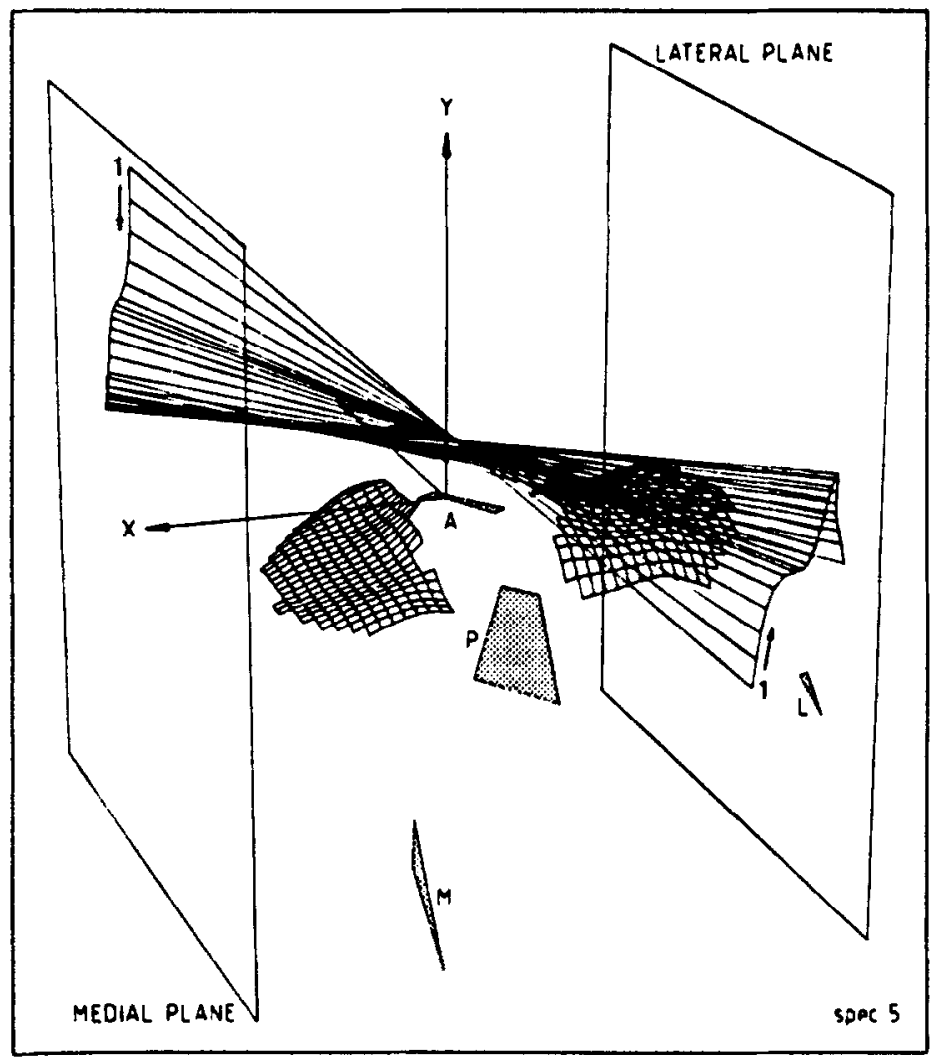

Fig. 2(a). 
(b)

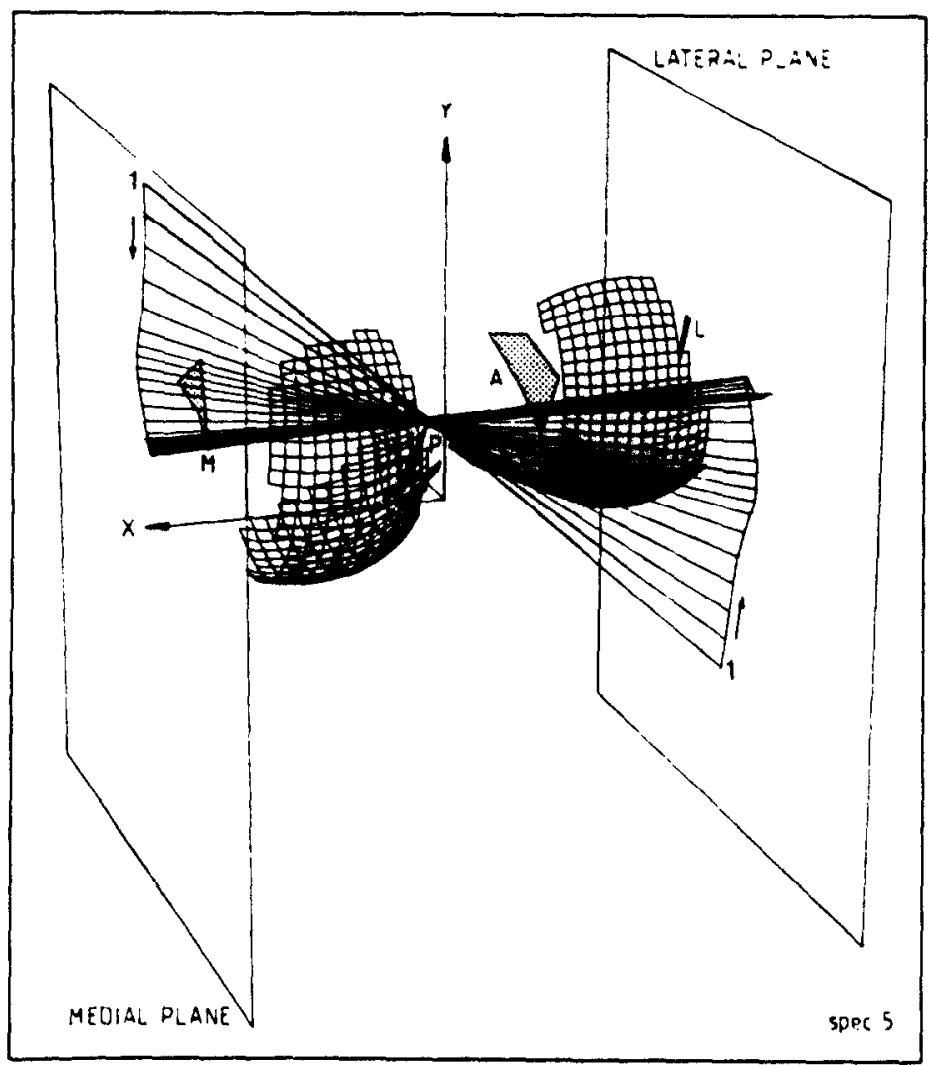

Fig. 2. A three-dimensional view from the postero-medial side on the finite helical axes for small motion steps along the internal envelope of motion of specimen 5 relative to the geometry and ligament insertions of the tibia (2a) and of the femur (2b). The endpoints of the axes are at the intersections with the medial and lateral sagittal planes, which are located $50 \mathrm{~mm}$ of the center of the knee. The first axis, indicated by 1 . represents the first llexion step. The arrow indicates where the subsequent axes are located. $A=$ anterior cruciate ligament; $P=$ posterior cruciate ligament; $L=$ lateral collateral ligament: $M=$ medial collateral ligament.

functions of flexion and the axis patterns for the internal motion pathway of a moving tibia relative to a fixed femur for three sets of motions steps taken from the additional experiment with specimen 5. Firstly [Fig. 3(a)], all subsequent positions were selected from the experiment and the helical axes were determined for small motion steps of 3-5 $5^{\circ}$ Secondly [Fig. 3(b)], a set of joint positions was selected in such a way that the resulting motion steps were similar to the motion steps of the experiments with specimens 1 and 2 . Thirdly [Fig. 3(c)], a set of joint positions was selected, resulting in large motion steps of similar size as the motion steps of the experiments with specimens 3 and 4. Hence, of the same motion pathway three representations were obtained, which reflected the effects of the choice of the number and size of the motion steps on the helical axes representations of the motion pathway. The pitches associated with the axes are shown in Fig. 4 as functions of flexion. It is evident when comparing the results in Figs 3 and 4 , that by using a larger motion step, the essential characteristics of the axis patterns are retained as compared to the motion with small motion steps. Hence. the axis patterns for the larger motion steps seem to be a good representation for a continuous motion pattern.
The finite helical axes for an internal and an external motion pathway of one specimen (specimen 1) are shown in Fig. 5 as projections on the horizontal and transversal planes together with the locations of the femoral insertions of ligaments and the contours of the femoral geometry. With respect to the locations relative to the ligament insertions and the articular geometry, the axis patterns of the other three specimens are very similar. The spatial patterns of the axes during flexion motions are also very reproducible among the four specimens, as is shown in Fig. 6, where the intersection patterns are given of all four specimens for both motion pathways.

For both motion pathways the similar general characteristics of helical axis patterns can be noticed. The first flexion steps are accompanied by axial rotation, hence the first axes are oblique if viewed in the frontal plane. As flexion progresses, the contribution of the axial rotation decreases and the axes become more horizontal. As viewed in the transversal plane, the axes move posteriorly above $70^{\circ}$ flexion. Measured in the mid-sagittal plane, the amount of posterior shift during the external motion pathway is $8 \mathrm{~mm}$ on the average, ranging between 7 and $9 \mathrm{~mm}$, and for the internal motion pathway is also $8 \mathrm{~mm}$ on the average, 

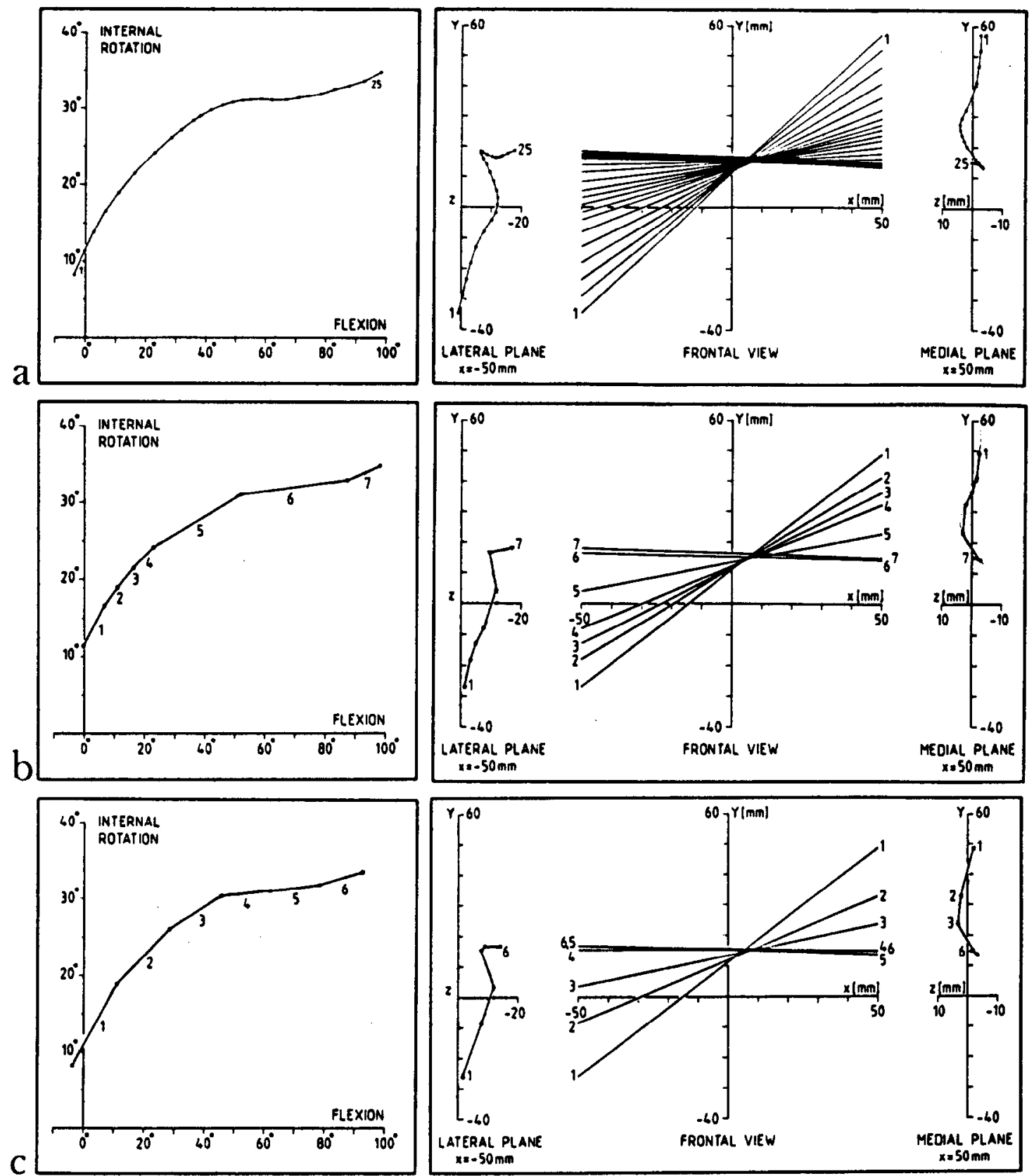

Fig. 3. The internal rotation as functions of flexion (left) and the corresponding finite helical axes (right). The helical axis are represented relative to the femoral coordinate system as a projection on the frontal plane, and as intersections with the medial and lateral sagittal planes (specimen 5 ). The three figures $\mathbf{a}, \mathbf{b}$ and $\mathbf{c}$ represent the same motion pathway, but for different selections of the motion steps. (a) All positions, small motion steps; (b) selected positions I, variable large motion steps; (c) selected positions II, large motion steps of approximately $15^{\circ}$.

ranging between 6 and $9 \mathrm{~mm}$. The difference between the internal and the external motion pathways is represented in the orientation of the axes, in the sense that the axial rotation is reversed, which gives a reversed oblique direction in the frontal plane. Another difference between the internal and external motion pathways is the somewhat different orientation in the transversal plane, in the sense that the lateral intersections are shifted $5 \mathrm{~mm}$ posteriorly with internal rotation as compared to external rotation (Fig. 6).

The helical translations are variable, partly due to the variable helical rotation steps between the specimens. The sum of the subsequent helical translations over the whole flexion motion from extension to $100^{\circ}$ flexion varies between 0.5 and $2.1 \mathrm{~mm}$ for the external motion pathway and between 2.5 and $3.9 \mathrm{~mm}$ for the internal motion pathway. The sum of the helical 


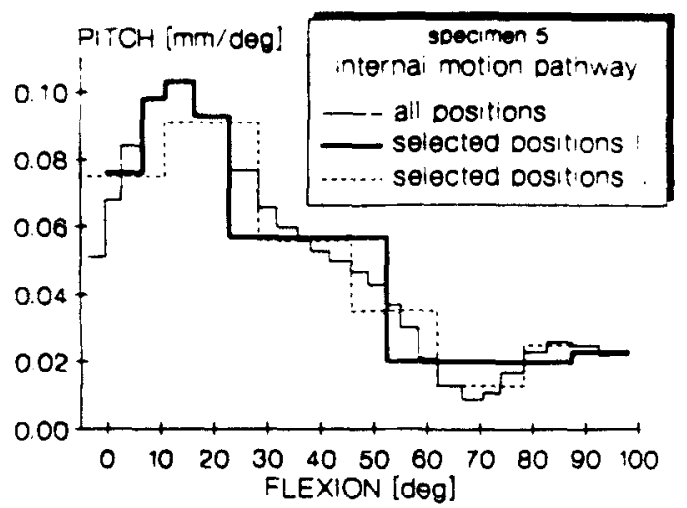

Fig. 4. The pitch as function of flexion, which is associated with the three sets of finite helical axes in Fig. 3: all positions and the selected positions I and II.

translation is positive, which means that the translation is directed medially. The pitch is positive over the whole flexion range, although it is small and sometimes barely exceeds the pitch error for the repeated reconstruction. For the internal motion pathway the pitch varies between 0.01 and $0.08 \mathrm{~mm}$ per degree, and for the external motion pathway the pitch varies between -0.03 and $0.05 \mathrm{~mm}$ per degree (Table 2).

\section{DISCUSSION}

Centers of rotation for planar motions, and helical axes for spatial motions of the human knee joint received ongoing interest from the early functional anatomists. like Weber and Weber (1836), to conlemporary biomechanicians. They served as a method to relate joint motions to the joint anatomy, particularly to the geometry of the ligaments and the articular surfaces, as was studied extensively in twodimensional analyses (e.g. Menschik, 1974: Huson. 1974). The relationships between the centers of rotation and the ligament geometry served as guidelines for the development of ligament reconstruction techniques (Müller, 1983).

For joints with more than one degree of freedom of motion, the motion axes are not unique but depend on the actual motion pathway. If the knee is considered as a system with at least two degrees of freedom of motion, i.e. flexion and axial rotation, with motion limits defined by the envelope of passive motion (Blankevoort et al., 1988), then different motions within the envelope can occur about different helical axes (Fig. 7). For example, pure flexion occurs about a horizontal axis, pure axial rotation about a vertical axis and a combination of these two about an oblique axis. The helical axes then depend on the particular motion pathway within the motion envelope. The second consequence of the envelope of motion is that only small loads are needed to move the joint within its motion envelope and, as a conseqeunce, the motions are very susceptible to small changes of external loaids.

If a planar motion is assumed within the envelope of freedom of motion, the motion should be precisely defined for obtaining adequate reproducibility of the

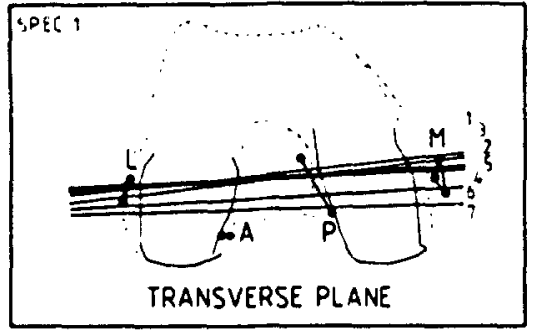

external motion pathway

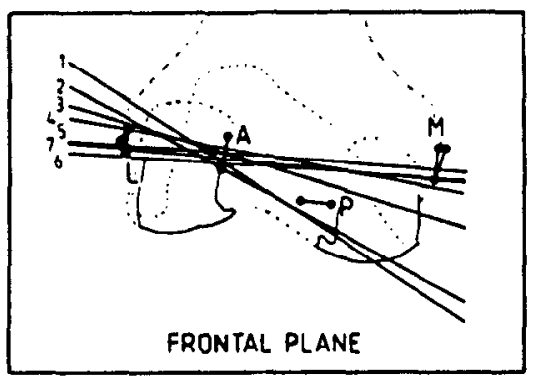

$\stackrel{10 \mathrm{~mm}}{\longrightarrow}$

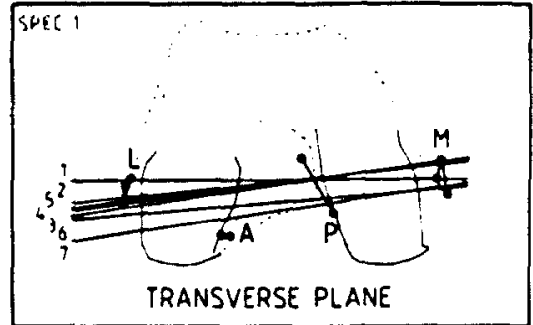

internal motion pathway

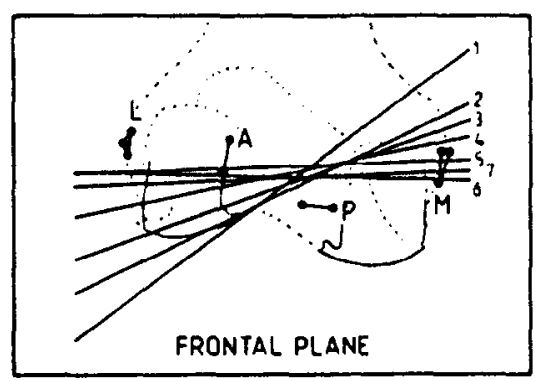

igm

Fig. 5. Helical axes of an external and an internal motion pathway of specimen 1 relative to the femoral ligament insertions and the femoral geometry (solid lines are measured contours; dashed lines are sketched contours). $\mathbf{A}=$ anterior cruciate ligament; $\mathbf{P}=$ posterior cruciate ligament; $\mathrm{L}=$ lateral collateral ligament; $\mathrm{M}=$ medial collateral ligament. 

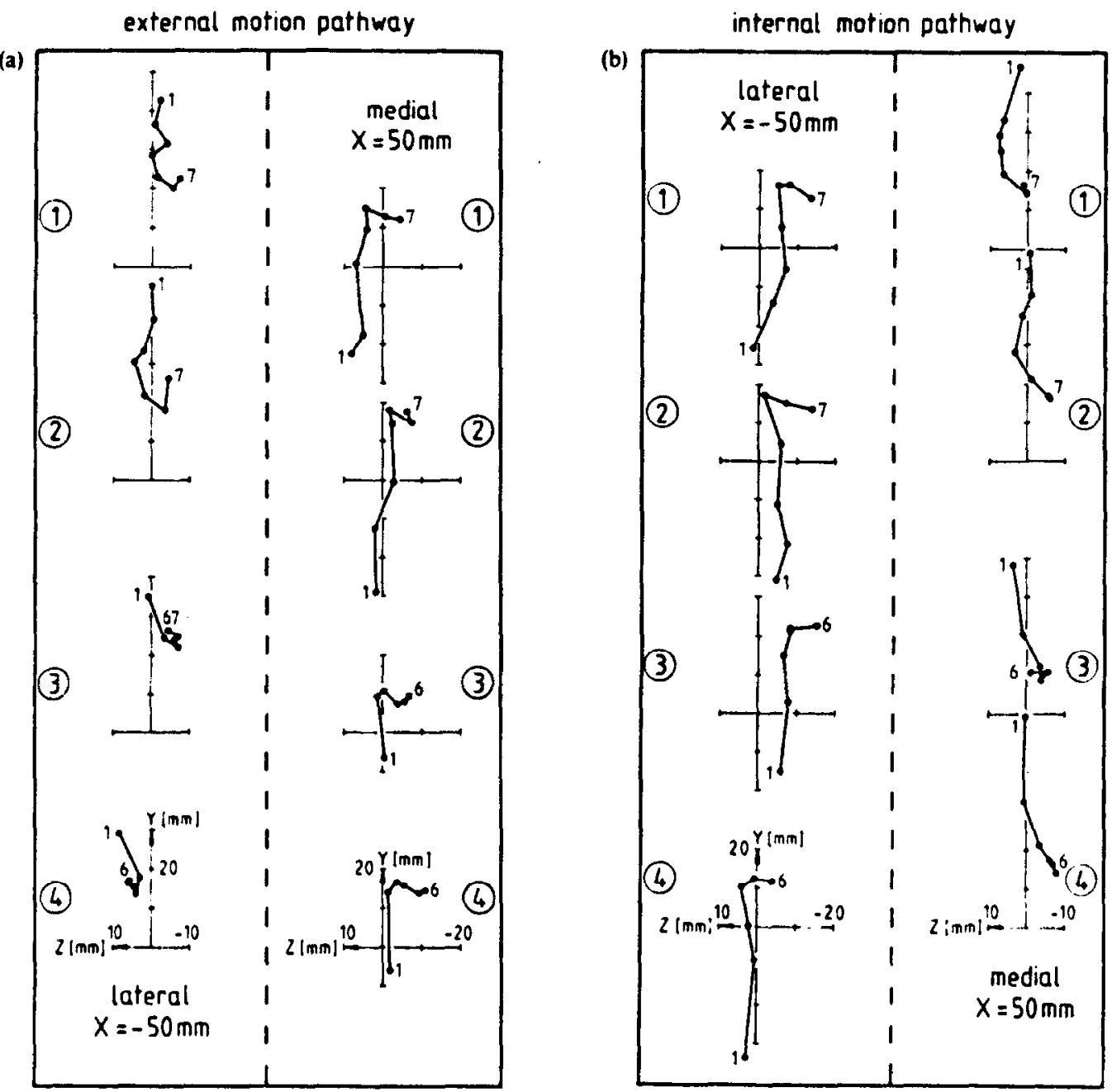

Fig. 6. The intersections of the helical axes with the medial and tateral sagittal planes of the four specimens. Moving tibia relative to fixed femur. (a) External motion pathway: (b) internal motion pathway.

centers of rotations. Hence, adequate positioning of the joint specimens and precise control of kinematic constraints should be applied for consistent motion pathways in a particular experiment. For different experiments, the planar motions will generally not be reproduced precisely. This may explain the variable results of the-centers of rotations for the knee among different authors (Frankel et al., 1971; Walker et al., 1972: Smidt, 1973; Harding et al.. 1977; Soudan et al., 1979), but inaccuracies in the measurement techniques may also have contributed to this.

The axis patterns reported for in vitro three-dimensional flexion motions were not very consistent (Blacharski et al., 1975; Harding and Blakemore, 1980; van Dijk, 1983). Some studies addressed the susceptibility of the helical axis to the accuracies of the experimental methods (Soudan et al., 1979; Duke et al., 1977) or discussed the error propagation during the computational process (Woltring et al., 1985; de Lange et al., 1990a), but the reported axis patterns in more accurate studies only represented the particular motion pathways within the envelope and were not reproducible hetween the studies (van Dijk, 1983; Hartfel et al.. 1987; Ramakrishnan et al., 1987). The comparison between the different studies seems inappropriate, as for example in comparing in vivo studies with in vitro studies, the conclusion may be drawn that the helical axis patterns in these studies depended mainly on the particular motion pathways and not on the inaccuracies of the measurement techniques and data processing.

Variations of the loading conditions, either caused by external factors such as external load control, or by internal factors such as anatomical variations between individuals, can cause large variations of motion pathways within the envelope of motion. It must also 
Table 2. The helical rotation and pitch associated with the finite helical axes for the internal and external motion pathways of the four knee specimens

\begin{tabular}{|c|c|c|c|c|c|}
\hline & \multirow[b]{2}{*}{$\begin{array}{l}\text { Axis } \\
\text { No. }\end{array}$} & \multicolumn{2}{|c|}{ Internal motion pathway } & \multicolumn{2}{|c|}{ External motion pathway } \\
\hline & & $\begin{array}{l}\text { Rotation } \\
\text { (degree) }\end{array}$ & $\begin{array}{c}\text { Pitch } \\
\text { (mm per degree) }\end{array}$ & $\begin{array}{l}\text { Rolation } \\
\text { (degree) }\end{array}$ & $\begin{array}{c}\text { Pitch } \\
\text { (mm per degree) }\end{array}$ \\
\hline \multicolumn{6}{|l|}{ Specimen 1} \\
\hline & 1 & 7.8 & -0.017 & 9.3 & 0.060 \\
\hline & 2 & 3.7 & -0.016 & 4.1 & 0.070 \\
\hline & 3 & 6.9 & 0.036 & 7.5 & 0.075 \\
\hline & 4 & 13.9 & 0.010 & 14.6 & 0.040 \\
\hline & 5 & 28.3 & 0.030 & 28.8 & 0.040 \\
\hline & 6 & 22.1 & 0.022 & 22.4 & 0.020 \\
\hline & 7 & 11.3 & -0.028 & 10.5 & 0.029 \\
\hline \multicolumn{6}{|l|}{ Specimen 2} \\
\hline & 1 & 8.2 & 0.009 & 9.4 & 0.027 \\
\hline & 2 & 3.9 & 0.026 & 4.4 & 0.055 \\
\hline & 3 & 7.2 & 0.048 & 7.9 & 0.014 \\
\hline & 4 & 13.8 & 0.033 & 14.8 & 0.039 \\
\hline & 5 & 28.5 & 0.016 & 28.5 & 0.034 \\
\hline & 6 & 25.6 & 0.005 & 23.1 & 0.029 \\
\hline & 7 & 7.3 & 0.076 & 9.9 & 0.026 \\
\hline \multicolumn{6}{|l|}{ Specimen 3} \\
\hline & 1 & 14.5 & -0.029 & 18.3 & 0.049 \\
\hline & 2 & 18.4 & -0.006 & 19.5 & 0.041 \\
\hline & 3 & 15.3 & 0.019 & 15.5 & 0.011 \\
\hline & 4 & 15.2 & 0.022 & 15.0 & 0.014 \\
\hline & 5 & 19,4 & 0.009 & 19.6 & 0.019 \\
\hline & 6 & 23.2 & 0.019 & 13.4 & 0.025 \\
\hline \multicolumn{6}{|l|}{ Specimen 4} \\
\hline & 1 & 15.6 & -0.001 & 18.4 & 0.033 \\
\hline & 2 & 18.4 & 0.007 & 19.3 & 0.039 \\
\hline & 3 & 14.9 & 0.023 & 15.2 & 0.022 \\
\hline & 4 & 14.6 & 0.009 & 14.7 & 0.011 \\
\hline & 5 & 18.4 & 0.009 & 18.5 & 0.019 \\
\hline & 6 & 14.5 & 0.015 & 14.5 & 0.022 \\
\hline
\end{tabular}

be recognized that in in vivo studies, the joint motion produced within the envelope of motion depends on the specific task that is performed, due to the variable muscle coordination and external loads. For example, motion pathways will be different between normal level walking and running. Reproducible axis patterns can only be found for the same motion pathways, which are reproducible in a sense that they are not susceptible to small load variations. In a previous study of Blankevoort et al. (1988) on passive knee joint motions, reproducible motions were found to be motions along the envelope of passive motion. The envelope of passive motion is relatively insensitive to moderate axial compression forces and AP-forces. In this study the choice was made to focus on finite helical axes for motions along the envelope of passive motion, i.e. flexion motion with either an internal or an external applied torque of $3 \mathrm{Nm}$. The positions and orientations of the subsequent finite helical axes relative to the joint anatomy were reproducible for each of these two motion pathways in the four tested joint specimens. The general characteristics were, to a certain extent, not affected by the magnitudes of the subsequent motion steps. The axes were oblique relative to all anatomic planes and reflected the combination of flexion and axial rotation.

The helical translation is a 'pure' translation as opposed to the translation of the origin of the moving body relative to the coordinate system of the fixed body, because the latter depends on the specific anatomic locations of the origins (Blankevoort et al., 1988). In the present experiments, the helical translation was expressed as the pitch, by normalizing the translation relative to the helical rotation. The pitch was found to be small and variable among the individual specimens. The variations may be explained by the pitch error for repetition of the experiment, which is relatively large as compared to the absolute pitch values. The pitch was directed medially and was more pronounced for the internal motion pathway as compared to the external motion pathway. This means that the knee makes a screw-like motion, combining the rotation about an axis with a translation along the axes. The posterior shift of the helical axis with increasing flexion is not related to the helical translation or the pitch, but is comparable to the 


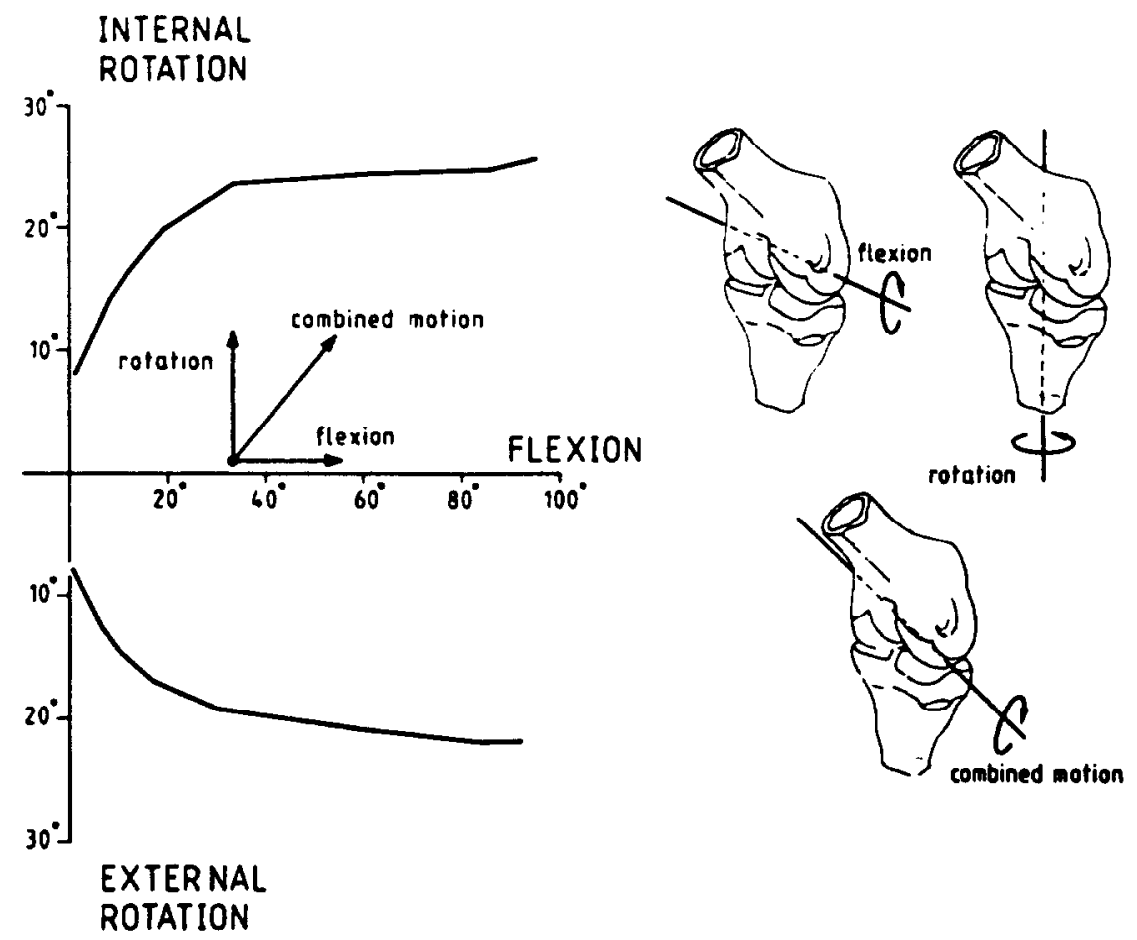

Fig. 7. The envelope of passive knee joint motion between extension and $95^{\circ}$ flexion with internal and external tibial torques of $3 \mathrm{Nm}$ (one specimen; from Blankevoort et al., 1988). The joint is free to move within its envelope in flexion and axial rotation. A fexion motion will occur about a horizontal axis; axial rotation of the tibia relative to the femur occurs about a vertically oriented axis. A combination of axial rotation and flexion will generally result in an oblique helical axis.

posterior shift of the instant center of rotation in the planar four-bar-linkage model (Strasser, 1917; Huson. 1974; Menschik, 1974).

In the planar four-bar-linkage model of the knee, the instant center of rotation is located at the intersection of the rigid bars which represent the anterior and posterior cruciate ligaments. In this study, the helical axes intersected, in nearly all cases, the space located in between the femoral insertions of the cruciate ligaments, which would suggest an important functional role for the cruciate ligaments for both internal and external motion pathways. But the actual recruitment of the ligaments should then be taken into account as well. For the external motion pathways the lateral (LCL) and medial (MCL) collateral ligaments are recruited, whereby a functional shift occurs from the posterior ligament fibers to the anterior fibers (Huiskes et al., 1984). For flexion angles higher than $40^{\circ}$, also the anterior bundle of the posterior cruciate ligament (PCL) is recruited for the external motion pathway (Huiskes et al., 1984). This means that for this motion, the motion control of the LCL, MCL and the PCL, in combination with the articular geometry, results in the particular pattern of helical axes as found in the present study (Fig. 5). It can be noticed that for external rotation the axes are closer to the $L C L$ and the $\mathrm{PCL}$ as compared to axes of the internal motion pathway. For the internal motion pathway, the anterior cruciate ligament (ACL), the posterior bundle of the PCL and the MCL are recruited (Huiskes $e t$ al., 1984), which may explain the axes being closer to the ACL insertions as compared to the external motion pathway. These observations suggest that the cruciate ligaments are not only responsible for the location of the helical axes, but that also the collateral ligaments may be important in this respect. The real value of the helical axes as a way to describe the functional relationships between passive knee joint motions and the anatomic structures may evolve from studies which use advanced mathematical models of the knee (Wismans et al., 1980; Blankevoort and Huiskes, 1987) taking into account compliant ligaments and their anatomic insertions and the geometry of the articular surfaces.

It is concluded that reproducible finite helical axes can be found for passive knee joint motions, provided that accurate measurement techniques are used and reproducible motion patterns are prescribed. The axes are not unique, but depend on the particular motion pathway. For internal and external motion pathways, the axes are oblique relative to all anatomic planes and reflect the combined occurrence of flexion and axial rotation. Their locations relative to the anatomic structures are reproducible among the different indi- 
vidual joint specimens. The axes move posteriorly above $70^{\circ}$ flexion. The helical translations are relatively small, but indicate a medial translation of the tibia relative to the femur with increasing flexion.

Acknowledgement-This research program was sponsored in part by Grant $90-90$ from the Netherlands Organization for Research (NWO/MEDIGON).

\section{REFERENCES}

Blacharski. P. A., Somerset, J. H., Murray. D. G. (1975) A three-dimensional study of the kinematics of the human knee. J. Biomechanics 8, 375-384.

Blankevoort. L. and Huiskes, R. (1987) Mathematical simulations of passive knee joint motions. Biomechanics: Basic and Applied Research (Edited by Bergmann, G., Kölbel. R. and Rohlmann, A.), pp. 285-290. Martinus Nijhoff. Dordrecht.

Blankevoort, L.. Huiskes, R. and Lange, A. de (1988) The envelope of passive knee joint motion. J. Biomechanics 21, $705-720$.

Dijk. R. van (1983) The behaviour of the cruciate ligaments in the human knee. Ph.D. dissertation. University of Nijmegen. The Netherlands.

Dijk, R. van, Huiskes, R. and Selvik, G. (1979) Ruentgenstereophotogrammetric methods for the evaluation of the three-dimensional kinematic behaviour and cruciate ligament length patterns of the human knee joint. J. Biomechanics 12,727-731.

Duke, R. P., Somerset. J. H, and Blacharski. P. (1977) Some investigations of the accuracy of knee joint kinematics. J. Biomechanics 10,659-673.

Frankel, V. H., Burstein, A. H. and Brooks, D. B. (1971) Biomechanics of internal derangement of the knee. Pathomechanics as determined by analysis of the instant centers of motion. J. Bone Ji Surg. 53A, 945-977.

Groud, E. S. and Suntaty. W. J. (1983) A joint coordinatto system for the clinical description of three-dimensional motions: applications to the knec. J. biumech. Engng 105, 136-144.

Harding. M. L. and Blakemore. M. E. (1980) The instant centre pathway as a parameter of joint motion-an experimental investigation of a method of assessment of knee ligament injury and repair. Engng Med. 9, 195-200.

Harding. M. L., Harding. L. and Goodfellow, J. W. (1977) A preliminary report of a simple rig to aid the study of the functional anatomy of the cadaver human knee joint. J. Biomechanics 10, 517-523.

Hartfel, M. A., Lysdahl. H. J.. Olson, D. G. and Erdman, A. G. (1987) The use of screw axis surfaces in the three dimensional analysis of the human knee joint. In 1987 Advances in Bioengineeriny (Edited by Erdman, A. G.) American Society of Mechanical Engineers, New York.

Huiskes. R., Blankevoort, L.. Dijk, R. van, Lange, A. de and Rens. Th. J. G. van (1984) Ligament deformation patterns in passive knee-joint motions. In 1984 Adeunces in Bioenyineering (Edited by Spilker, R. L.). pp. 53-54. American Society of Mechanical Engineers, New York.

Huiskes, R., Kremers, J., Lange, A. de, Woltring. H. J., Selvik,
G. and Rens. Th. J. G. van (1985) An analytical stereophotogrammetric method to determine the three-dimensional geometry of articular surfaces. $J$. Biomechanics 18 , $559-570$.

Huson, A. (1974) Biomechanische Probleme des Kniegelenks. Orthopädie 3, 119-126.

Lange, A. de, Huiskes, R. and Kauer, J. M. G. (1990a) Measurement errors in Roentgen-stereophotogrammetric joint-motion analysis. J. Biomechanics 23, 259-269.

Lange, A. de, Huiskes, R. and Kauer, J. M. G. (1990b) Effects of data smoothing on the reconstruction of helical axis parameters in human joint kinematics. J. biomech. Engny 112, 107-113.

Meijer, R. C. M. B., Huiskes R. and Kauer. J. M. G. (1989) A stereophotogrammetric method for measurements of ligament structure. J. Biomechanics 22, 177-184.

Menschik, A. (1974) Mechanik des kniegelenkes. Z. Orthop. $112,481-495$.

Mikhail. E. M. (1976) Obsertations and Least Syuare's. DunDonneley, New York.

Müller. W. (1983) The Knee. Form. Function and Liqument Reconstruction. Springer. Berlin.

Ramakrishnan. H. K., Wootten, M. E., Gorton. G., Kadata. M. P. and Cochran. G. V. B. (1987) Three-dimensional helical axis estimation in the study of knee joint mechanics. Pric. 33rd A. Mig Orthop. Res. Soc.. p. 202.

Selvik, G. (1974) A Roentgenstereophotogrammetric method for the study of the kinematics of the sheletal system. Ph.D. dissertation. University of Lund. Sweden.

Shiavi, R., Limbird. T., Frazer. M.., Stivers, K., Strauss, A. and Abramovitz, J. (1987a) Helical motion analysis of the knec - I. Methodology for studying kinematics during locomotion. J. Biemechanics 20. $459-469$.

Shiavi. R.. Limbird. T., Frazer. M., Stivers, K.. Strauss, A. and Abramovitz, J. (1987b) Helical motion analysis of the knee II. Kinematies of uninjured and injured knees dur ing walking and pivoting. J. Biomechanics 20,653-665

Smidt, G. L. (1973) Biomechanical analysis of knee Dexion and extension. J. Biomerchanics 6, 7992.

Soudan, K., Van Audekercke, R. and Martens, M. (1979) Methods, difficulties and inaccuracies in the study of human kintmatics and pathokinematics by the instant axis concept. Example: the knee joint. J. Biomechanics 12, 27-33.

Strasser, H. (1917) Lehrbuch de Muskel-und Gelenkmechanik. Springer, Berlin.

Walker, P. S., Shoji, H. and Erkman, M. J. (1972) The rotational axis of the knee and its significance to prosthesis design. Clin. Orthop. Rel. Res. 89, 160-167.

Weber, W. and Weber, E. (1836) Mechanik der Menshlichen Gehwerkzeuge, teil Il. pp. 161-202. Über das Kniegelenk, Göttingen.

Wismans, J., Veldpaus, F., Janssen, J., Huson, A. and Struben P. (1980) A three-dimensional mathematical model of the knee-joint. J. Biomechunics 13, 677-685.

Woltring. H. J. (1986) A Fortran package for generalized, cross-validatory spline smoothing and differentiation. Adv. Engng Software 8, 104-113.

Woltring. H. J., Huiskes, R., Lange, A. de and Veldpaus, F. E. (1985) Finite centroid and helical axis estimation from noisy landmark measurements in the study of human joint kinematics. J. Biomechanics 18, 379-389. 